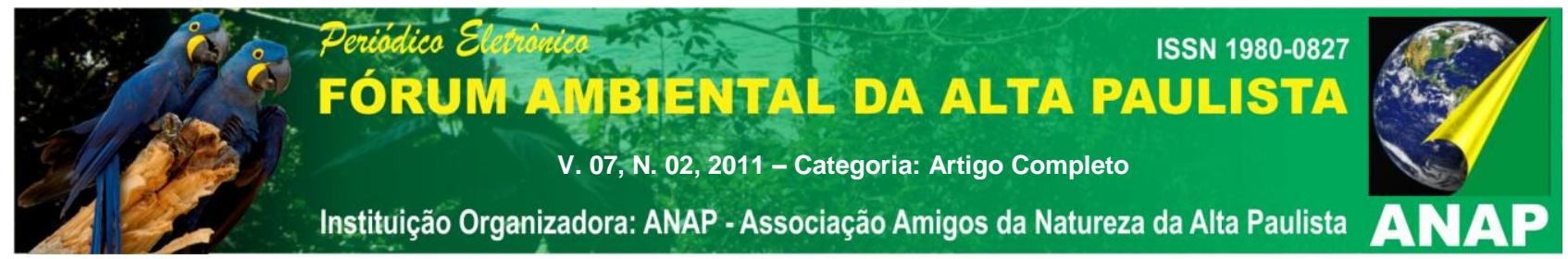

\title{
NASCENTES: ANÁLISE E DISCUSSÃO DOS CONCEITOS EXISTENTES
}

\author{
Pedro Henrique Vaz Pereira ${ }^{1}$
}

Sueli Yoshinaga Pereira ${ }^{2}$

Alberto Yoshinaga ${ }^{3}$

Paulo Ricardo Brum Pereira ${ }^{4}$

RESUMO: O presente estudo buscou reunir definições encontradas em bibliografias específicas bem como as resoluções de âmbito nacional sobre nascentes, com a intenção de ampliar o debate sobre este tema tão importante na gestão dos recursos hídricos e ambiental. O trabalho consistiu em um levantamento de diversas fontes de divulgação do conhecimento tanto em forma de livros acadêmicos quanto de endereços eletrônicos e glossários internacionais de renome no meio científico. Apoiados neste resgate de literatura buscaram-se definir alguns conceitos básicos, podendo considerar que as nascentes são surgências que possuem vazão suficiente para originar curso ou acúmulo de água. O estudo deve detalhar os diferentes modos de ocorrência das nascentes, quanto à forma, vazão, origem, bem como estabelecer algumas diretrizes em relação a sua caracterização e estudo de seu comportamento dinâmico. Destaca-se a importância da preservação da mata ciliar estipulada por lei bem como no controle da dinâmica das transformações no uso e ocupação do solo das áreas a montante.

Palavra chave: Nascentes, conceitos, análises.

\section{INTRODUÇÃO}

\footnotetext{
${ }^{1}$ Geografo, Mestrando, Instituto de Geociências - UNICAMP. Email: pedropereira@ige.unicamp.br

${ }^{2}$ Geóloga. Professor Doutor, Instituto de Geociências - UNICAMP. Email: sueliyos@ige.unicamp.br.

${ }^{3}$ Arquiteto. Email; betoyoshinaga@gmail.com.

${ }^{4}$ Geografo. Doutor. Instituto Florestal - SMA. Email: paulobrumpereira@ig.com.br
} 


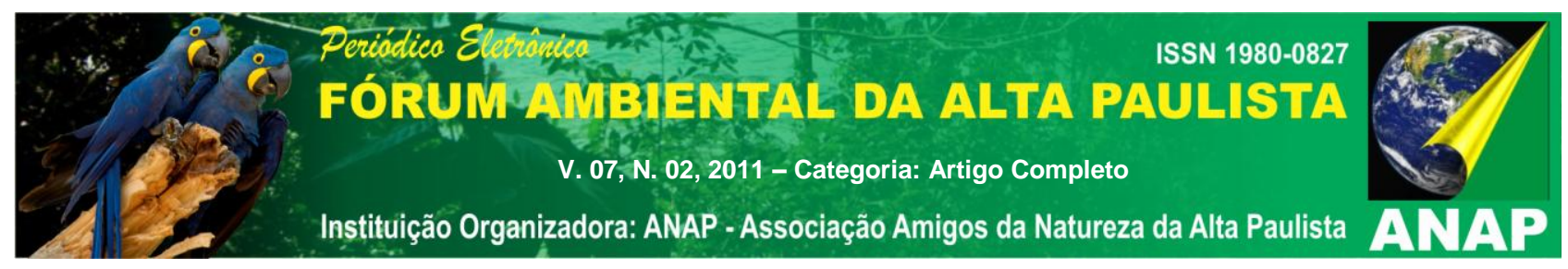

O presente artigo visa apresentar uma análise relativa à definição de nascentes baseadas nas bibliografias existentes no sentido de subsidiar estudos sobre o assunto e esclarecimentos relativos a sua caracterização.

Assim foi realizado um levantamento em livros acadêmicos, endereços eletrônicos e glossários internacionais no sentido de reunir o maior número de definições.

São raros estudos mais aprofundados sobre o assunto, e portanto, este artigo visa reunir os conceitos existentes na bibliografia técnica, analisá-las e discuti-las sob a ótica do conhecimento existente.

\section{DEFINIÇÕES E CONCEITOS RELATIVOS}

Os estudos sobre nascentes ainda são escassos na literatura científica. Entende-se comumente que as nascentes são afloramentos do nível freático na superfície do terreno, e são pontos iniciais de cursos de água.

De acordo com o Dicionário Aurélio, nascente significa "fonte de um curso de água, cabeceira".

Em livros básicos de hidrogeologia, cita-se Davis \& De Wiest (1966) que define "fonte" (spring) como "qualquer descarga superficial natural de água suficientemente grande para fluir em um pequeno curso de água. Valores de descarga menor que isto é denominado de percolação superficial (surface seepage)".

Kresic (2007) define fonte (spring) como "o local na superfície da terra onde há descarga de água subterrânea do aquifero, criando um fluxo visível. Quando o fluxo não é visível, mas a superfície é úmida quando comparada à área do entorno, então a descarga de água subterrânea é denominada de percolação (seep). Fontes formadas por um conjunto dessas percolações (seepage spring) é definida quando a descarga de água atravessa pequenos poros intergranulares de sedimentos inconsolidados (por ex. areia e cascalho). Essa fonte geralmente é marcada por uma abundante vegetação e ocorre comumente em vales que cortam a jusante da zona de saturação de um depósito de camada aqüífera uniforme. Ainda são definidas Fontes por fraturas (ou fissuras) referentes às descargas de água ao longo de planos de acamamentos, juntas, clivagens, falhas e outras quebras nas rochas consolidadas". 


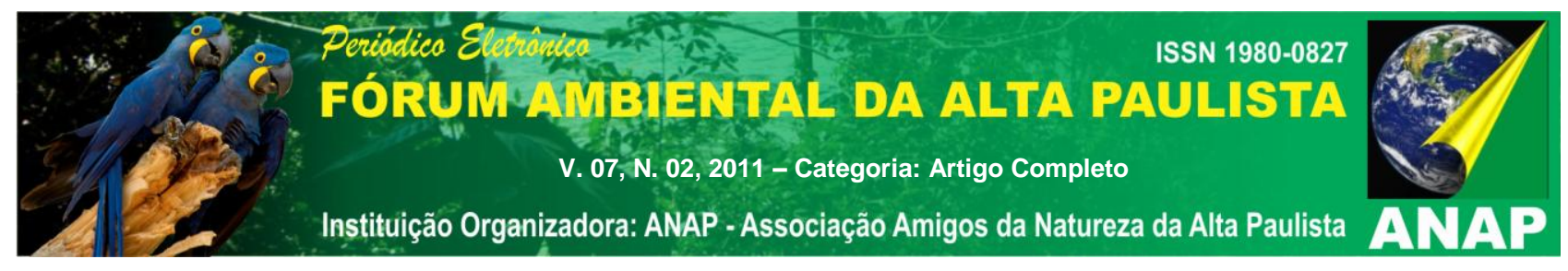

A Figura 1 apresenta as várias formas de nascentes existentes e definidas em Davis e De Wiest (1966).

Ainda segundo Davis e DeWiest (1966), existem várias propostas de classificação das fontes, baseadas em características diversas, sendo as mais comuns:

- A vazão de descarga;

- Características da carga hidráulica (pressão), que cria a descarga;

- Estrutura geológica que controla a descarga, e

- Qualidade e temperatura da água.

Assim, é apresentada também a classificação de Meinzer (1923 apud Davis e DeWiest 1966), baseada nas faixas de vazão de descarga na fonte. Esta classificação é apresentada na Tabela 1. 

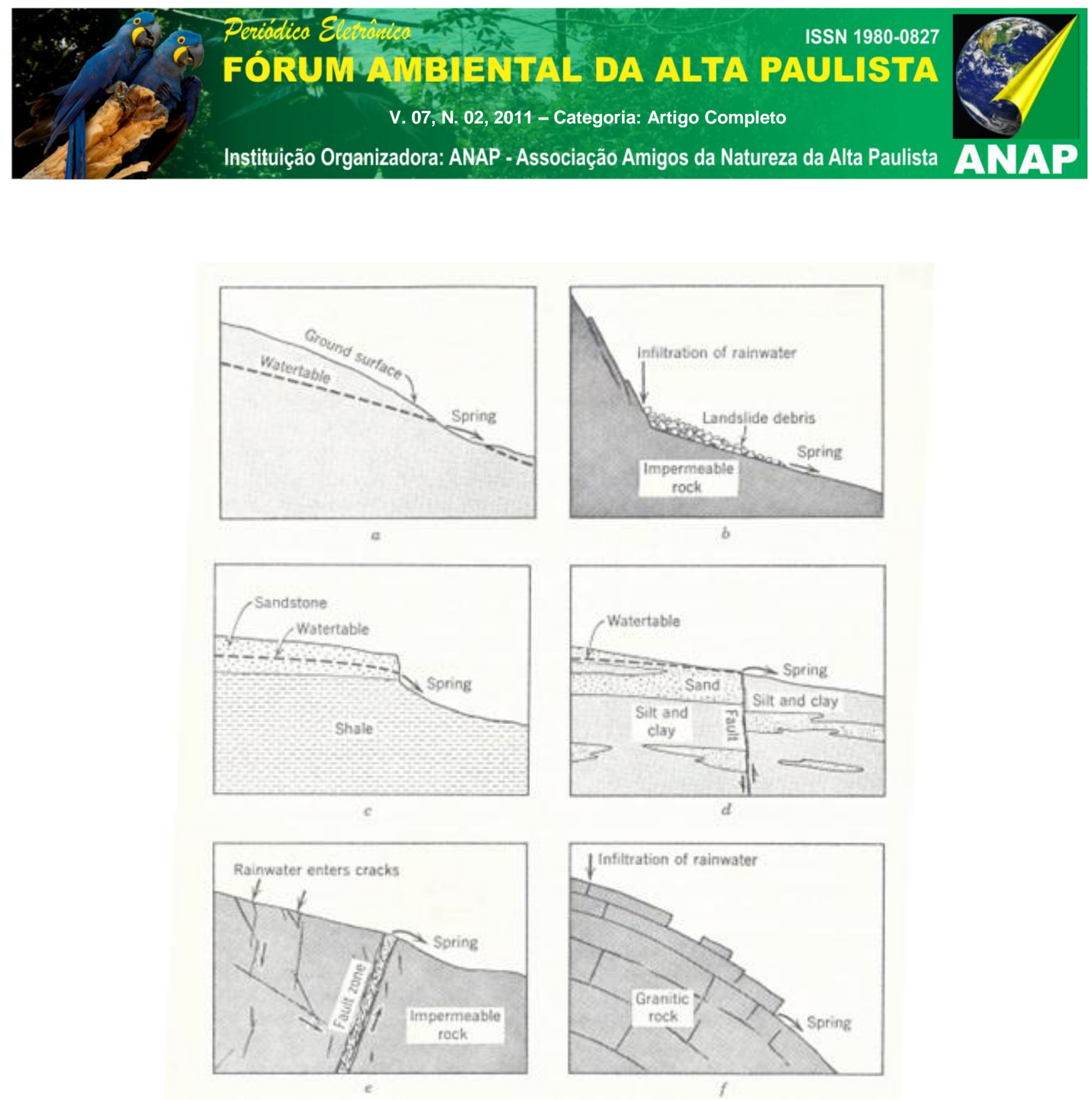

Figura 1 - Diversas ocorrências de fontes de acordo com o material geológico (Davis e DeWiest 1966). (a) depressão do terreno que intercepta o nível de água; (b) infiltração da água de chuva em material grosseiro e permeável no sopé de escarpa; (c) arenito permeável sobreposto a camada de argila; (d) uma falha que coloca camadas impermeáveis contra camadas permeáveis em aluviões; (e) uma falha que forma zonas abertas fraturadas nas rochas cisalhadas; (f) fraturas de resfriamento em rochas graníticas.

Tabela 1 - Classificação de fontes baseadas na taxa média de descarga (Meinzer 1923 apud Davis e DeWiest 1966).

\begin{tabular}{||l|l|l|l||}
\hline MAGNITUDE & \multicolumn{1}{|c|}{ DESCARGA } & MAGNITUDE & \multicolumn{1}{c||}{ DESCARGA } \\
\hline Primeira & $10 \mathrm{~m}^{3} / \mathrm{s}$ ou maior & Quinta & 1 a $10 \mathrm{~L} / \mathrm{s}$ \\
\hline Segunda & $1 \mathrm{a} 10 \mathrm{~m}^{3} / \mathrm{s}$ & Sexta & $0,1 \mathrm{a} 1 \mathrm{~L} / \mathrm{s}$ \\
\hline Terceira & $0,1 \mathrm{a} 1 \mathrm{~m}^{3} / \mathrm{s}$ & Sétima & 10 a $100 \mathrm{~cm}^{3} / \mathrm{s}$ \\
\hline Quarta & $10 \mathrm{a} 100 \mathrm{~L} / \mathrm{s}$ & Oitava & Menor que $10 \mathrm{~cm}^{3} / \mathrm{s}$ \\
\hline
\end{tabular}




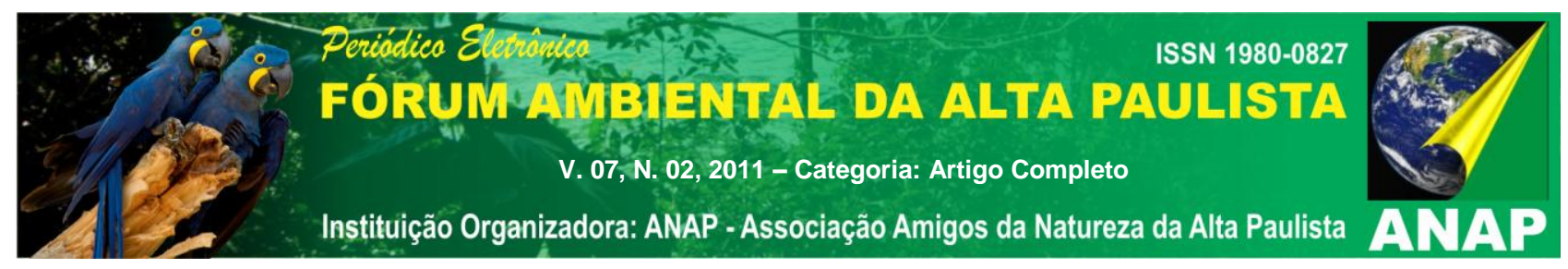

Calheiros et al. (2004) descreve nascente como "o afloramento do lençol (sic) freático, que vai dar origem a uma fonte de água de acúmulo (represa), ou cursos d'água (regatos, ribeirões e rios). A nascente ideal é aquela que fornece água de boa qualidade, abundante e contínua, localizada próxima do local de uso e de cota topográfica elevada, possibilitando sua distribuição por gravidade, sem gasto de energia. É bom ressaltar que, além da quantidade de água produzida pela nascente, é desejável que tenha boa distribuição no tempo, ou seja, a variação da vazão situe-se dentro de um mínimo adequado ao longo do ano. Esse fato implica que a bacia não deve funcionar como um recipiente impermeável, escoando em curto espaço de tempo toda a água recebida durante uma precipitação pluvial. Ao contrário, a bacia deve absorver boa parte dessa água através do solo, armazenála em seu lençol (sic) subterrâneo e cedê-la, aos poucos, aos cursos d'água através das nascentes, inclusive mantendo a vazão, sobretudo durante os períodos de seca. Isso é fundamental, tanto para o uso econômico e social da água - bebedouros, irrigação e abastecimento público, como para a manutenção do regime hídrico do corpo d'água principal, garantindo a disponibilidade de água no período do ano em que mais se precisa dela".

Ainda segundo estes mesmos autores, as nascentes podem ser classificadas como:

Nascente ou olho d'água - pode ser o tipo de nascente sem acúmulo d'água inicial, comum quando o afloramento ocorre em um terreno declivoso, surgindo em um único ponto em decorrência da inclinação da camada impermeável ser menor que a da encosta. São exemplos desse tipo as nascentes de encosta e de contato

Veredas - são formadas por várias nascentes espalhadas de modo difuso, numa área de afloramento. (Figura 3)

Nascentes com acúmulo inicial - quando a camada impermeável fica paralela a parte mais baixa do terreno e, estando próxima a superfície, acaba por formar um lago.

A Figura 2 apresenta as diversas formas de nascentes, de acordo com Calheiros et al. (2004) 

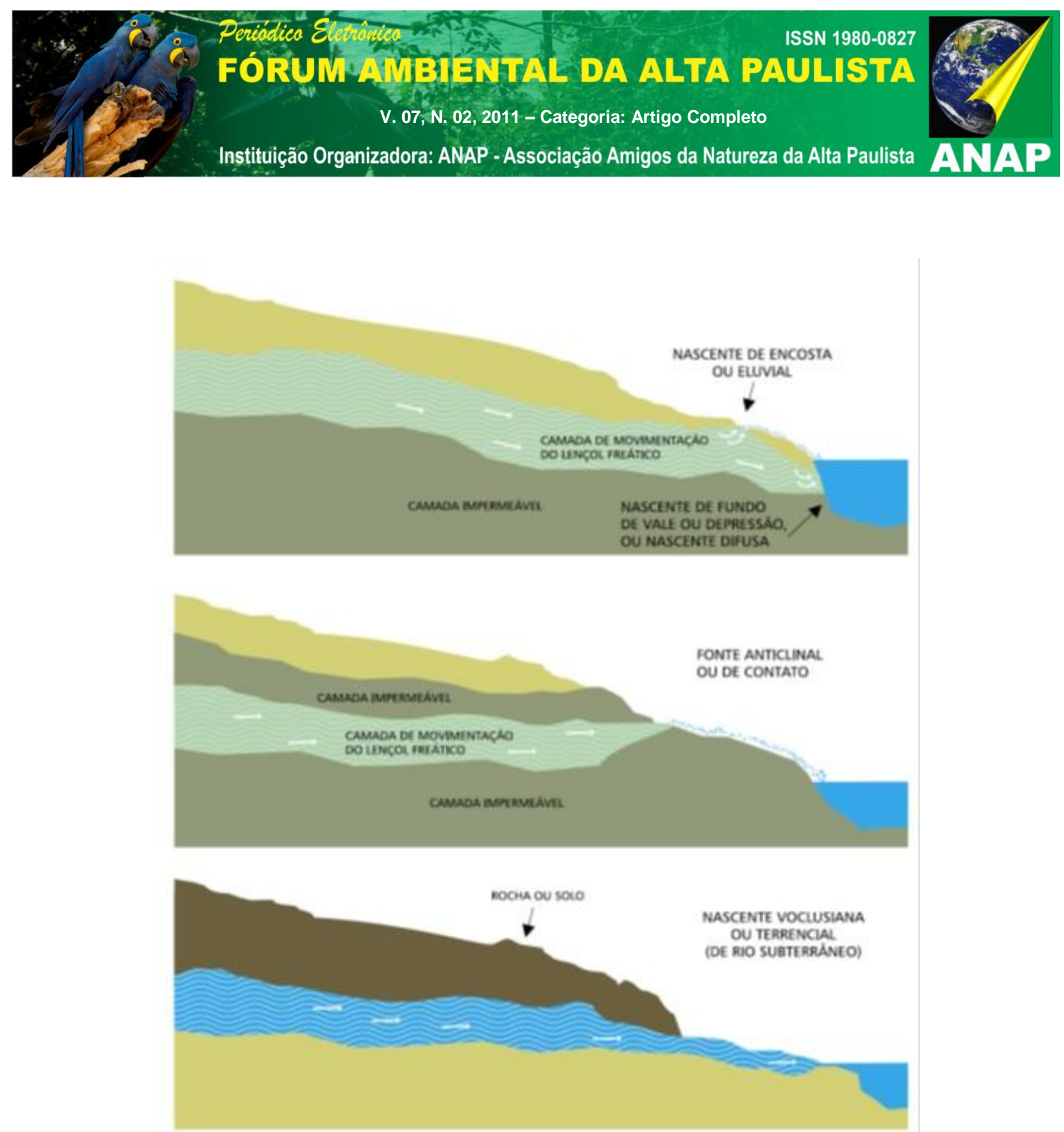

Figura 3 - Tipos mais comuns de nascentes originárias de aquifero não confinado: de encosta, de fundo de vale, de contato e de rio subterrâneo (carste) (Linsley e Franzini, 1978, apud Calheiros et al 2004).

O Glossário Hidrológico da UNESCO, (2011) apresenta as seguintes definições:

- Fonte: (1) origem de um rio; (2) em dinâmica de fluidos, ponto (ou linha) de onde divergem as linhas de corrente.

- Fonte difusa: nascente que emana de um meio permeável para uma área relativamente extensa.

- Nascente: local de onde a água emerge naturalmente, de uma rocha ou do solo, para a superfície do solo ou para uma massa de água superficial. 


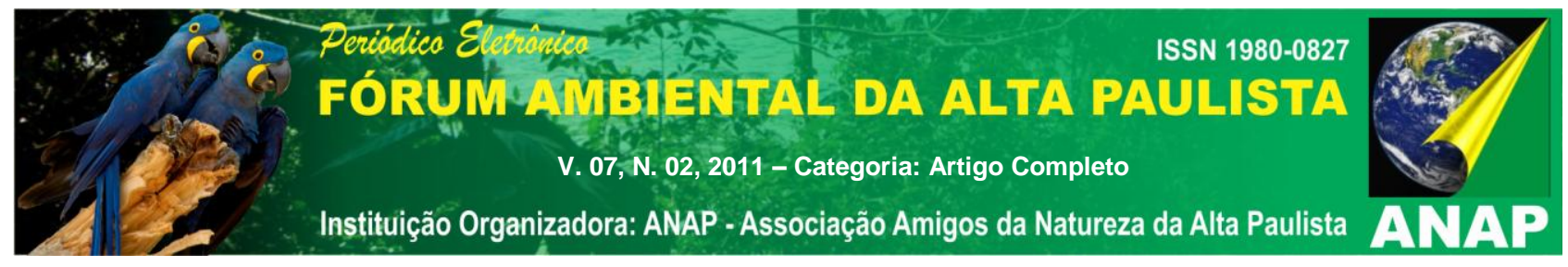

- Nascente artesiana: nascente cuja água provém de um aquífero artesiano, geralmente através de uma fissura ou outro tipo de abertura da formação impermeável que delimita o aquífero.

- Nascente de contato: nascente em que a água flui de uma formação permeável subjacente a uma formação relativamente impermeável.

- Nascente de depressão (sin. Nascente de gravidade): nascente que emerge para uma superfície, devido apenas ao fato dessa superfície interceptar o nível do aquífero.

- Nascente intermitente (sin. Nascente periódica): nascente cuja vazão se produz apenas em certos períodos cessando em outros.

- Nascente de falha geológica: nascente alimentada por água subterrânea profunda que emerge de uma falha de grande dimensão.

- Nascente de fissura: nascente que surge de uma fissura.

- Nascente de fratura: nascente que flui da fratura de uma rocha.

- Nascente mineral: nascente cuja água contem quantidades significativas de sais minerais

- Nascente termal (sin. Nascente termomineral): nascente cuja água tem uma temperatura superior à temperatura anual média do local onde ela emerge.

- Nascente vauclusiana: ressurgência em regiões cársticas que é controlada por um sifão natural e com funcionamento intermitente.

A Resolução CONAMA n 303 de 20 de março de 2002 dá a definição de "nascente" e sua área de proteção:

Art. $2^{\circ}$ - Para os efeitos desta Resolução, são adotadas as seguintes definições:

II - nascente ou olho d água: local onde aflora naturalmente, mesmo que de forma intermitente, a água subterrânea;

Art. 3o - Constitui Área de Preservação Permanente a área situada: 


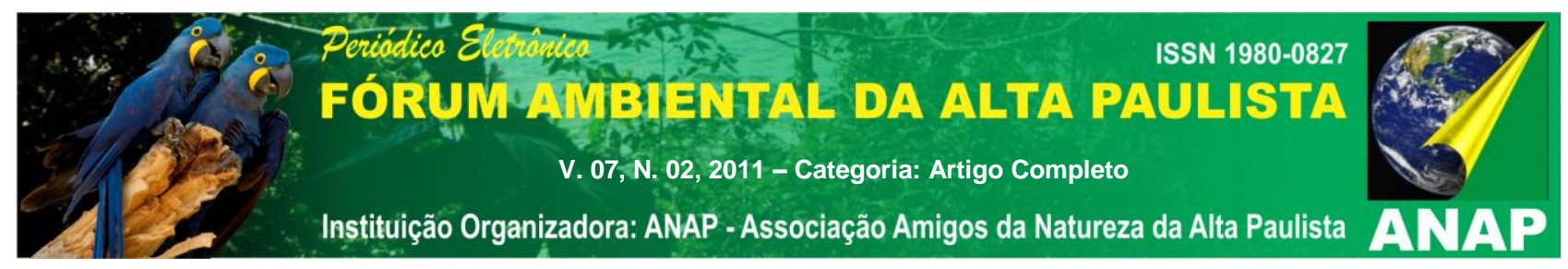

II - ao redor de nascente ou olho d'água, ainda que intermitente, com raio mínimo de cinqüenta metros de tal forma que proteja, em cada caso, a bacia hidrográfica contribuinte;

O (IBGE, 2004) em seu Vocabulário Básico de Recursos Naturais e Meio Ambiente dá a definição de "rio intermitente":

"Rio intermitente é curso d'água que circula em certas épocas do ano, sendo alimentado por água de nascentes, por águas superficiais ou até mesmo pela fusão da neve. Comum em regiões semiáridas".

Em artigo publicado pelo geólogo Santos, (2009), denominado "As APPs associadas a nascentes: O que é uma nascente? Como identificá-la?”, define-se a caracterização de uma nascente:

\begin{abstract}
"Vale a pena chamar a atenção para duas situações que normalmente confundem os observadores e os têm muitas vezes levado a equivocadamente as caracterizar como nascentes, com decorrente aplicação das disposições legais de uma APP, quando efetivamente não se trata de uma nascente". A primeira refere-se a terrenos localmente de topografia plana ou bastante suave, com dificuldade natural de escoamento superficial de águas de chuva. Há nessas situações a possibilidade de formação de uma camada sub-superficial de argilas hidromórficas que, por sua grande impermeabilidade, dificultam a infiltração e proporcionam a sustentação de uma camada superficial saturada ou úmida, especialmente em períodos chuvosos. São situações que sugerem, erroneamente, uma classificação como nascente difusa. Outro caso controverso diz respeito a olhos d'água intermitentes originados de águas de infiltração que, ao atravessar a zona superior do solo (zona de aeração) encontram obstáculos com menor permeabilidade ou mesmo impermeáveis, decorrentes da existência de variações geológicas internas horizontais ou sub-horizontais (uma lente argilosa, por exemplo, ou algum tipo de estrutura). Nessas condições essas águas de infiltração podem resultar na formação de "lençóis suspensos" ou "empoleirados" e acabam aflorando à superfície de um terreno declivoso antes de atingir o lençol freático propriamente dito. Uma situação que, pelas definições conceituais estabelecidas, também não pode ser caracterizada como uma nascente, ainda que sugira cuidados especiais de proteção.
\end{abstract}

A legislação brasileira, quando se refere ao barramento de rios permanentes, está de acordo com os princípios ecológicos e com a legislação americana (RIPARIAN RIGHTS), segundo o "Parecer Técnico referente à Construção de Barragens em Talvegues com fluxo de água" dos engenheiros agrônomos Afranio Almir Righes \& Gilberto Luiz Marin Righi: 


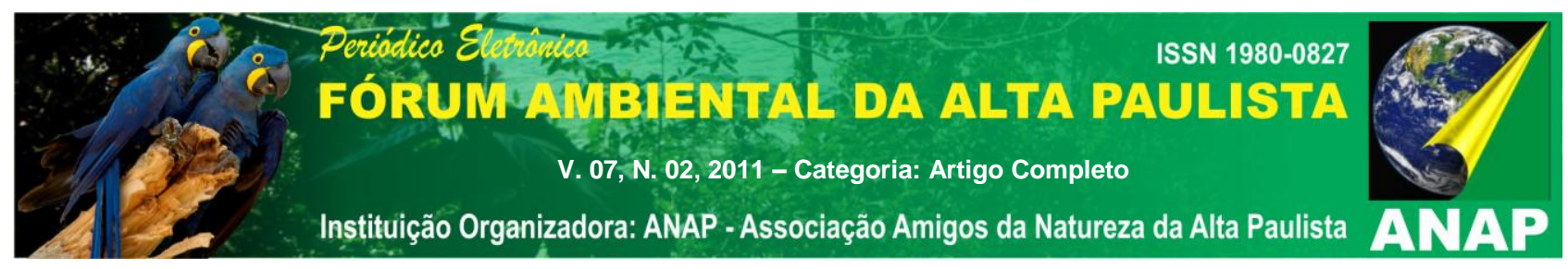

\begin{abstract}
"Talvegues (Linha que segue a parte mais baixa do leito de um canal ou vale) com fluxo de água intermitente (somente quando ocorrem precipitações com intensidades superiores à taxa de infiltração de água no solo) não podem ser interpretados como rios intermitentes. O escoamento superficial ou enxurrada é um evento efêmero e somente ocorre quando o solo estiver saturado e não tem capacidade para conduzir toda a água da chuva para o seu interior, perdendo-se por escoamento superficial."
\end{abstract}

Neste caso, alguns chamam este escoamento superficial de "rios temporários", que só ocorrem após as chuvas e que, evidentemente, não possuem nenhuma contribuição da superfície freática e na maioria dos casos, nem a sua calha é bem definida. Porém, tais rios temporários sequer merecem a distinção de rios, haja vista a incapacidade de suportarem uma fauna aquática permanente e significativa.

Assim sintetizam-se as seguintes definições:

- Rio intermitente - aqueles cursos d'água, que possuem, quando em deflúvio, uma contribuição do aquifero freático.

- Linha de Drenagem Superficial - só ocorrem após as chuvas e não possuem nenhuma contribuição do aquifero freático.

\title{
3. DISCUSSÃO
}

O conceito de nascentes ou seu sinônimo (fontes - como visto em diversas literaturas e glossários técnicos) tem sua definição como a descarga natural de água suficientemente grande para fluir em pequeno curso de água, ou na definição de Calheiros, que pode dar origem a uma fonte de acúmulo (represa ou regatos, ribeirões e rios).

$\mathrm{Na}$ maioria dos casos, as nascentes tem sua origem no afloramento da superfície freática, e sua surgência pode ocorrer de várias maneiras (pontual, difusa, por veredas, etc..).

No entanto, acredita-se que cada fonte deva ser caracterizada também de acordo com a proposta de Davis e DeWiest (1966), ou seja, com a determinação da vazão de 


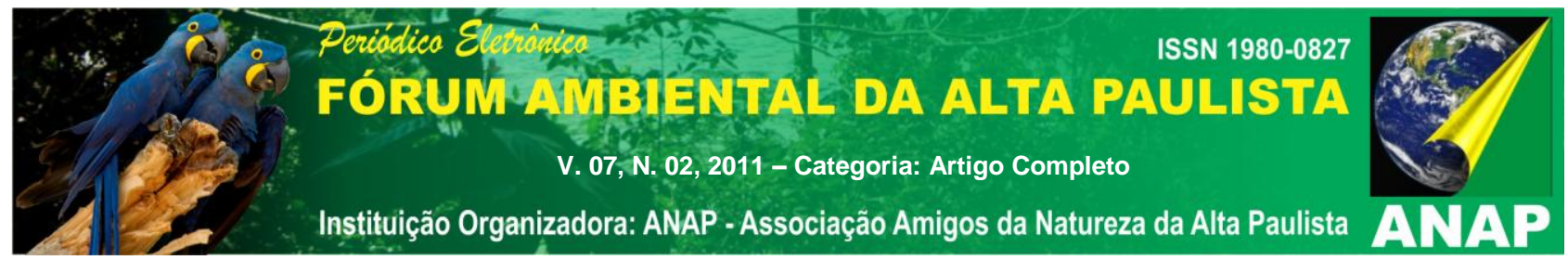

descarga, características hidráulicas, estruturas geológicas e qualidade e temperatura das águas.

A classificação de Meinzer (1923 apud Davis e DeWiest 1966) em função da magnitude da vazão é a única encontrada na literatura científica e que pode ser utilizada para classificação das nascentes brasileiras.

O trabalho de Calheiros et al (2004) é uma das únicas referências brasileiras encontradas especificamente sobre nascentes, e a classificação proposta (olho d'água, veredas e de acumulo inicial) é em função da forma de surgência principalmente.

No entanto, na Resolução CONAMA (303, de 20 de março de 2002), a nascente é definida como afloramento natural de água subterrânea (mesmo de forma intermitente). Essa definição abarca dessa maneira quase todas as ocorrências de surgência de água subterrânea, inclusive aquelas relativas aos aquíferos suspensos. Na definição do CONAMA a condição de fluxo e formação de corpos de água não são estabelecidas.

A definição técnica deixa claro que a nascente deve ter ocorrência natural e com vazão suficiente para fluir em curso de água ou a fonte de acúmulo.

Dessa forma a nascente é a descarga (pontual ou não) da água subterrânea, de onde se inicia um curso de água, que pode ser monitorada periodicamente e analisada por meio hidrógrafa (gráfico vazão versus tempo). Esta hidrógrafa pode contribuir para o melhor entendimento daquele ponto de surgência e de sua área de drenagem, das condições de recarga e descarga a montante da nascente.

As nascentes também possuem relação direta com a precipitação, evapotranspiração e infiltração, e assim seus pontos de afloramento podem mover-se de acordo com a variação da superfície freática. Isso implica que as nascentes podem se movimentar durante o ano hidrológico, bem como sua vazão variar também em função desses parâmetros citados.

Por fim, caso aplicar o modelo de Horton (1933, 1934 apud Fetter 2001), existem na questão de drenagens intermitentes, os fluxos de subsuperficie (interflow), que ocorrem na zona não saturada do solo e de suas surgências próximos aos corpos de água (return 


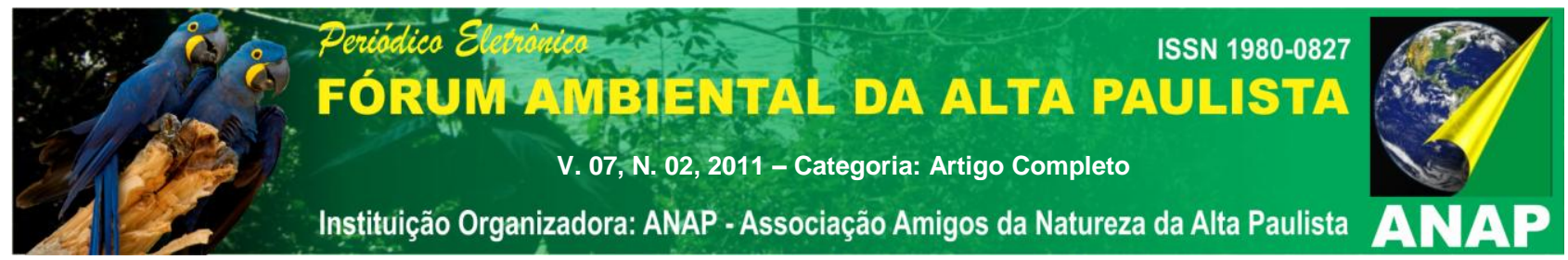

flow), em períodos chuvosos. Nestes casos, não se poderiam classificá-las como nascentes, porém pode haver uma caracterização falha nestes tipos de ocorrências, assim como na ocorrência das linhas de drenagem superficiais.

As nascentes, surgências de superfície freática, possuem uma relação direta com a cobertura vegetal. A supressão da vegetação nas áreas próximas das nascentes e nas margens dos rios provoca alterações adversas no comportamento dessas ocorrências, pois a vegetação é fundamental para a recarga do aquifero freático, e a água percolada acaba aflorando nas nascentes e olhos d’água. A retirada da vegetação nas áreas de nascentes determina seu desaparecimento, pois as condições de infiltração são reduzidas e aumentadas o escoamento superficial. Consequentemente, há o assoreamento no canal de drenagem e a diminuição da contribuição do fluxo de base no corpo de água superficial.

O uso e ocupação do solo tanto em áreas rurais quanto urbanas vem ao longo dos tempos impactando profundamente na rede de drenagem, por isso a proteção das áreas de nascente é a intenção da legislação ambiental.

As nascentes de fraturas profundas podem possuir águas termominerais, minerais ou termais, e geralmente são águas que se infiltram e surgem de modo artesiano em condições especiais. Estas surgências podem possuir altas vazões e originar rios de porte. É o caso das fontes do Balneário de Águas de Lindóia, principalmente a Fonte São Roque, com vazões de $50 \mathrm{~m}^{3} / \mathrm{h}$, e que origina o ribeirão das Águas Quentes, que corta a porção central do município (Yoshinaga, 1990). Nestes casos, as áreas de recarga destas fontes profundas geralmente são grandes áreas a montante, definidas após estudos hidrogeológicos.

\section{CONCLUSÕES}

As nascentes apresentam definições que se convergem a essa definição geral: são surgências que possuem vazão suficiente para originar curso ou acúmulo de água. 


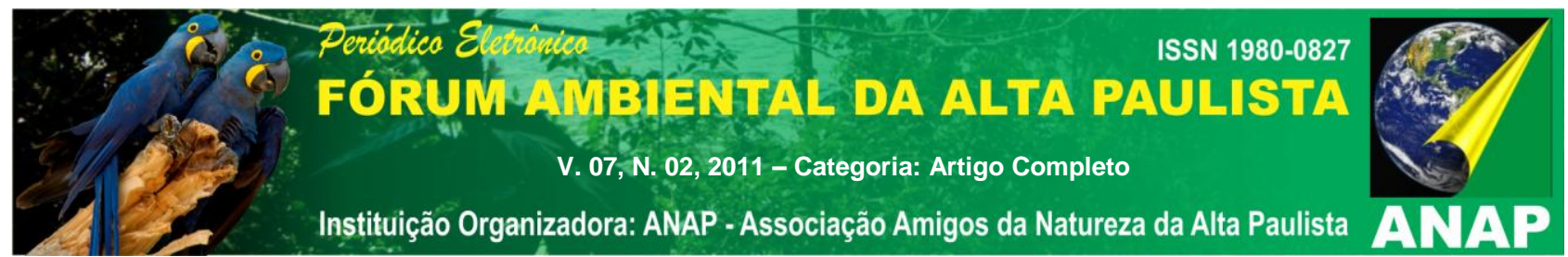

A caracterização das nascentes devem ser fundamentadas por estudos relativos a sua vazão, condições geológicas e hidrogeológicas de ocorrência, qualidade e temperatura.

O estudo do comportamento das vazões em função do monitoramento das vazões ao longo do ano hidrológico é fundamental para o entendimento da dinâmica das águas, de suas condições de recarga e descarga, bem como de suas variações na qualidade e temperatura.

Em casos de nascentes de afloramento da superfície freática, a presença da vegetação original proporciona condições de recarga e armazenamento, pois favorece o processo de infiltração das águas de chuva, e assim garante a manutenção da vazão.

A não preservação dessas condições na nascente e seu entorno, provoca seu desaparecimento, como é visto em várias paisagens no Brasil, pois sem capacidade de infiltração, não existe recarga e há assoreamento no canal de drenagem.

As definições apresentadas neste trabalho não divergiram em relação a sua conceituação e sim detalharam os diferentes modos de ocorrência das nascentes, quanto a forma, vazão, origem, bem como estabeleceu algumas diretrizes em relação a sua caracterização e estudo de seu comportamento.

Por fim, destaca-se que estas ocorrências possuem uma dinâmica que se modifica em função da sazonalidade, mas também das transformações no uso e ocupação das terras a montante.

\section{REFERÊNCIAS}

CONAMA. Legislação ambiental. Disponível em http://www.mma.gov.br/ conama . Acesso em 19 de outubro de 2010.

CONSELHO NACIONAL DO MEIO AMBIENTE. Resolução CONAMA no 303 de 20/03/2002

DAVIS, S.N. \& DEWIEST, R.J.M.. Hydrogeology. John Wiley \& Sons. 1966. 463 pp 


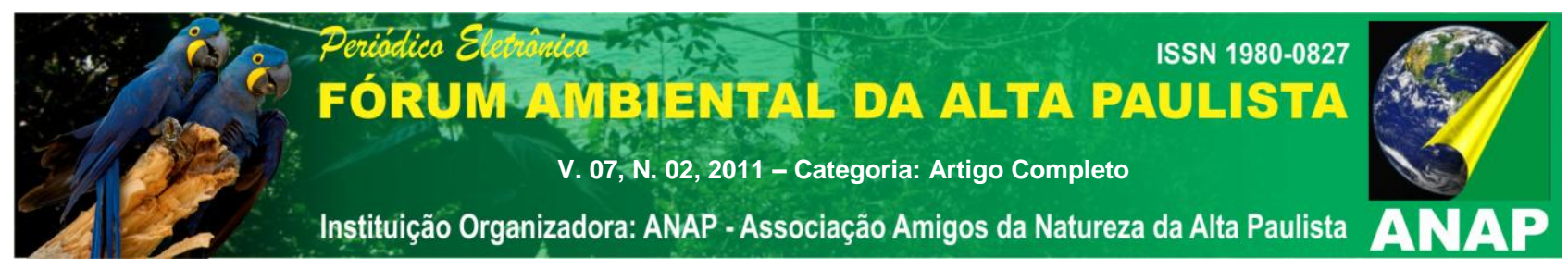

FETTER, C.W. 2001. Applied Hydrogeology. Prentice-Hall. New Jersey. 598pp.

IBGE. Vocabulário Básico de Recursos Naturais e Meio Ambiente. (2004). Site:

http://www.ibge.gov.br/home/presidencia/noticias/vocabulario.pdf, acesso em 28 de março de 2011

KRESIC, N. Hydrogeology and Groundwater Modelling. 2nd. Edition. CRC Press (Taylor and Francis Group). 807 pp. 2007.

RIGHES, A. A. \& RIGHI, G. L. M. (2006). Parecer Técnico referente à Construção de Barragens em Talvegues com Fluxo de Água.

SANTOS, A. R. dos (2009). As APPs associadas a nascentes: O que é uma nascente? Como identificá-la? Site: http://www.ecodebate.com.br/ 2009/07/21/as-apps-associadas-anascentes-o-que-e-uma-nascente-como-identifica-la-artigo-de-alvaro-rodrigues-dossantos/, acesso em 28 de março de 2011.

UNESCO. Glossário Internacional de Hidrogeologia. Disponível em: (http://webworld.unesco.org/water/ihp/db/glossary/glu/PT/GF1166PT.HTM. Acesso em 12 de agosto de 2011).

YOSHINAGA, S. 1990. "Estudos Hidrogeológicos, Hidrogeoquímicos e Isotópicos em Águas Minerais dos Municípios de Águas de Lindóia e Lindóia - SP". Dissertação de Mestrado. Instituto de Geociências, Universidade de São Paulo". 90 pp. 